\title{
A PRODUÇÃO DAS VOGAIS MÉDIAS TÔNICAS DO PORTUGUÊS (L2) POR FALANTES NATIVOS DO ESPANHOL
}

THE PRODUCTION OF STRESSED MID VOWELS OF PORTUGUESE (L2) BY NATIVE SPEAKERS OF SPANISH

\author{
Susiele Machry da Silva ${ }^{1}$
}

Resumo: Este artigo versa sobre a aquisição das vogais médias tônicas do Português Brasileiro (PB) - L2 - por falantes nativos do espanhol da América. A investigação, pautada nas diferenças fonológicas que as duas línguas apresentam quanto ao sistema vocálico tônico, analisa o processo de aquisição desses aprendizes quanto à produção do contraste fonológico entre as vogais médias /e/ - /E/ e/o/ - / /, em oposições do tipo seco - seco, soco - soco, observadas no português e não no espanhol. O corpus, oriundo da amostra Machry da Silva (2014), é constituído por doze (12) imigrantes nativos dos países Argentina e Uruguai e domiciliados, no momento da pesquisa, no Brasil. Os resultados permitem verificar que os hispano-falantes apresentam dificuldade para produzir o contraste fonológico, com tendência a realizar as vogais médias [E] e [o] de acordo com os padrões acústicos das vogais já existentes na língua nativa, no caso as vogais [e] e [o].

Palavras-chave: produção; vogais médias; segunda língua.

Abstract: This article discusses the acquisition of the stressed mid vowels of Brazilian Portuguese (L2) by native speakers of Latin American Spanish. The investigation, which is guided by the phonological differences between the stressed vowel system of the two languages, analyses the acquisition process by Spanish-speaking learners regarding the production of the phonological contrast between the mid vowels /e/ - / / / and /o/ - /o/ observed in Portuguese (s/e/co - s/e/eco and s/o/co-s/o/co), but not in Spanish. The corpus consists of 12 Argentinean and Uruguayan immigrants who were living in Brazil at the time of this research. The results allow us to verify that Spanish speakers experience difficulties in producing the phonological contrast and they tend to produce [c] and [o] according to the vowel acoustic patterns of their native language, that is, [e] and [o].

Keywords: production; mid vowels; second language .

1 Doutora em Linguística pela PUCRS. Professora assistente da Universidade Católica de Pelotas. 


\section{Introdução}

No processo de aprendizagem ${ }^{2}$ de uma Segunda Língua (L2), a aquisição dos aspectos fonético-fonológicos apresenta-se como um dos mais salientes desafios a ser enfrentados por aprendizes. A realização fonética dos segmentos da L2, por falantes não nativos, frequentemente diverge dos padrões da língua nativa. Nesse sentido, de acordo com Strange e Shafer (2008), é comum que aprendizes de L2, principalmente quando adquirem a língua na fase adulta, apresentem uma pronúncia marcada dos segmentos da língua-alvo. Essa dificuldade de aquisição fonológica é muitas vezes atribuída à transferência dos padrões da língua nativa, já categorizados, para a L2.

As dificuldades de pronúncia apresentadas por aprendizes de L2 podem ser interpretadas, com base nas hipóteses previstas pelo Modelo de Aprendizagem de Fala - SLM (FLEGE, 1995, 2007), como a tendência de o aprendiz fazer perceptualmente uma "classificação de equivalência" dos sons da língua-alvo com os sons já existentes em sua língua nativa. Por esse entendimento, quando encontra similaridade entre um segmento a ser adquirido na L2 com um som já categorizado na Língua Materna (L1), a pressuposição é de que o aprendiz tenha dificuldade em reconhecer o som perceptualmente e, consequentemente, também o pronuncie com as qualidades fonéticas de sua língua nativa.

Embora nem todos os problemas de pronúnica estejam necessariamente relacionados com a percepção inadequada, o fato é que, principalmente nos estágios iniciais da aquisição, a língua materna e a L2 compartilham de um mesmo espaço fonológico (FLEGE, 1995; BEST; TYLER, 2007), o que fará com que os sistemas se influenciem mutuamente, resultando na transferência dos padrões fonéticos da língua nativa para a L2, em aquisição.

Uma vez que o aprendiz ao adquirir a fonologia da língua-alvo tende a buscar a "equivalência" dos sons dessa língua com sons de sua língua materna, presupõe-se, seguindo a proposta de Flege $(1995,2007)$, que quanto mais próximos foneticamente são os sons das línguas envolvidas, L1 e L2, mais provável será de ocorrer influência de um sistema sobre o outro e, por conseguinte, mais difícil resultará o processo de aquisição. Frente a isso, a proposta deste estudo é investigar, a partir de uma descrição acústica, a produção das vogais médias tônicas do Português (L2) por falantes nativos do espanhol da América, mais especificamente dos países Uruguai e Argentina, imersos ao Português Brasileiro (PB), variedade de fala de Porto Alegre.

2 Este estudo não faz distinção entre os termos 'aprendizagem' e 'aquisição', nem entre 'segunda língua' e 'língua estrangeira'. 
A língua espanhola, diferentemente do português, não possui em seu sistema vocálico uma categoria intermediária de vogais médias baixas (/ع/ e / //), não fazendo, portanto, a distinção fonológica em formas como seco seco, soco - soco. Nesse caso, dada a semelhança e a proximidade fonética entre as duas categorias, vogais médias-altas [e] e [o] e vogais médias-baixas $[\varepsilon]$ e [0], o hispano-falante ao adquirir o português, frequentemente, apresenta dificuldade na aquisição do contraste (ALLEGRO, 2004, 2010; FEIDEN; ALVES; FINGER, 2014; MACHRY DA SILVA, 2014), com tendência a interpretar as vogais / $\varepsilon /$ e / $/$ com base nas vogais /e/ e /o/, presentes em sua língua materna. Essa percepção “inadequada”, e a consequente não formação de uma categoria independente para as vogais do $\mathrm{PB}$, não existentes no espanhol, pode resultar em uma pronúncia da L2 desviante do falar nativo.

Com base no entendimento de que aprendizes de L2 necessitam ajustar seu espaço fonético para alocar os sons da língua-alvo, não presentes na LM (FLEGE, 1995, 2007), tem-se o propósito de, com este estudo, verificar se os bilíngues, nativos da Argentina e nativos do Uruguai, na produção das vogais do $\mathrm{PB}$, apresentam categorias distintas para as vogais médias-baixas $(/ \varepsilon /-/ \mathrm{o} /)$, ou, se essas vogais ocupam o mesmo espaço das vogais médias-altas (/e/ - /o/).

A partir da hipótese de que a pronúncia das vogais médias por não nativos, nativos do Uruguai e nativos da Argentina, difere da produção de falantes nativos do $\mathrm{PB}$ principalmente com relação aos parâmetros de altura e de anterioridade/posterioridade (MACHRY DA SILVA, 2014), a análise deste estudo é realizada com base nos valores dos dois primeiros formantes vocálicos: F1 (altura) e F2 (anterioridade). De posse dos valores obtidos para esses dois primeiros formantes, investiga-se a Distância Euclidiana entre as vogais, procurando-se verificar o quanto se distinguem na fala de não nativos os pares de vogais $[\mathrm{e}]-[\varepsilon]$ e [o] - [0]. Além de investigar em que medida o grupo de bilíngues é hábil para produzir a distinção entre vogais médias-altas e vogais médias-baixas do PB em formas como seco- séco, soco-sóco, esta proposta objetiva analisar possíveis diferenças de comportamento, entre os grupos de participantes investigados, quanto à produção dessas vogais.

\section{Caracterização acústica das vogais no português e no espanhol}

Estudos acústicos sobre as vogais do Português Brasileiro e sobre as vogais do Espanhol, nas variedades da Argentina e do Uruguai, não são em grande número até o momento. Com referência às vogais do $\mathrm{PB}$, pode-se mencionar os estudos de Moraes, Callou e Leite (1996) e o estudo de Mei- 
relles (2011), os quais, dentre outras variedades do PB, oferecem uma caracterização acústica das vogais na cidade de Porto Alegre, variedade aqui em exame. Sobre a variedade do espanhol da América, faz-se referência aos estudos de Aronson et al. (2000), com caracterização acústica das vogais na variedade de fala da Argentina, e o recente estudo de Santos e Rauber (2014), que oferece uma descrição acústica das vogais de Montevidéo - Uruguai.

As vogais tônicas do PB, de acordo com o estudo de Meirelles (2011), podem ser organizadas em três grupos: vogais anteriores [i, e, $\varepsilon$ ], posteriores baixas $[0, a]$ e posteriores altas $[0, u]$. No que tange às vogais médias, foco deste estudo, a autora, em conformidade com Moraes, Callou e Leite (1996), ressalta que as diferenças entre as vogais médias-altas [e] e [o] e as vogais

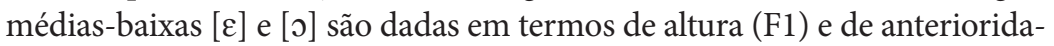
de (F2). Em termos de F1, altura, observa-se que as vogais [e] e [o] mostram-se mais altas em relação às vogais [ $[\varepsilon]$ e [0]; já em relação à F2, anterioridade/ posterioridade, a vogal [e] apresenta-se mais anterior em relação à vogal $[\varepsilon]$, e a vogal [o] levemente mais posterior em relação à vogal [0].

No caso do espanhol, variedade da América, de forma semelhante ao português, os estudos de Aronson et. al (2000) e Santos e Rauber (2014) indicam que as cinco vogais da língua podem ser bem caracterizadas por meio dos primeiros formantes, mais precisamente, F1 e F2. Com base nos autores, pode-se assumir que nessa língua há um sistema representado pelas vogais [i], [u] e [a], que ocupam as extremidades, e as vogais [e] e [o], que ocupam uma posição intermediária. Nessa língua, portanto, embora possam ser encontradas ocorrências de variações formânticas para as vogais médias [e] e [o], com F1 assumindo valores mais baixos em determinados contextos (NAVARRO TOMÁS, 1982 [1981]), não há tendência a uma diferença contrastiva entre vogais abertas e fechadas, como no Português Brasileiro.

Diante das características acústicas dos dois sistemas em análise, português e espanhol, o presente estudo parte do entendimento de que, para produzir o contraste entre as vogais médias-altas [e] e [o] e as vogais médias-baixas $[\varepsilon]$ e $[0]$ do $\mathrm{PB}$, o falante nativo do espanhol necessita adquirir, majoritariamente, os padrões de altura e de anterioridade/posterioridade.

\section{Metodologia}

Esta pesquisa constitui-se de um trabalho descritivo e experimental que tem como objetivo principal analisar a produção das vogais médias do Por- 
tuguês Brasileiro, em posição de acento tônico, por falantes nativos do espanhol, variedade da Argentina e do Uruguai. Nas seções seguintes, que explicam o método, são fornecidas informações sobre a seleção dos informantes, os instrumentos aplicados e os procedimentos de análise dos dados.

\subsection{Informantes}

A amostra, constituída a partir do banco de dados obtidos por Machry da Silva (2014), é composta por doze (12) informantes nativos dos países Argentina e Uruguai. Para participar da pesquisa, esses informantes deveriam ter migrado para o Brasil com ou após os 18 anos de idade; possuir, no momento da pesquisa, idade entre 18 e 69 anos; e estar residindo em Porto Alegre ou na região metropolitana dessa cidade ${ }^{3}$.

Além do grupo experimental, que constitui o objeto de análise deste estudo, foi selecionado um grupo controle, formado por doze (12) nativos do Português Brasileiro, mais precisamente da variedade de Porto Alegre. O propósito de incluir esse grupo na análise foi de obter um diagnóstico comparativo da produção das vogais tônicas por informantes não nativos, em relação à produção dos nativos. O Quadro 1 a seguir apresenta a estratificação dos grupos com base nas variáveis País, Sexo e Idade (variável contínua).

\begin{tabular}{|c|c|c|c|c|c|c|c|c|}
\hline \multicolumn{9}{|c|}{ Grupo Experimental } \\
\hline \multicolumn{2}{|c|}{ País de Origem } & \multicolumn{4}{|c|}{ Sexo } & \multicolumn{3}{|c|}{ Idade } \\
\hline Argentina & Uruguai & \multicolumn{2}{|c|}{ Argentina } & \multicolumn{2}{|c|}{ Uruguai } & Média & \multicolumn{2}{|c|}{$\begin{array}{c}\text { Desvio Padrão } \\
\text { (DP) }\end{array}$} \\
\hline \multirow[t]{2}{*}{6} & 6 & $\mathrm{~F}$ & M & $\mathrm{F}$ & M & \multirow[b]{2}{*}{36,82} & \multirow{2}{*}{\multicolumn{2}{|c|}{12,36}} \\
\hline & & 3 & 3 & 3 & 3 & & & \\
\hline \multicolumn{9}{|c|}{ Grupo controle } \\
\hline \multicolumn{4}{|c|}{ País_Brasil } & \multicolumn{2}{|c|}{ Sexo } & \multicolumn{3}{|c|}{ Idade } \\
\hline \multicolumn{4}{|c|}{ Porto Alegre } & \multicolumn{2}{|l|}{$\mathrm{F}$} & \multicolumn{2}{|c|}{ Média } & DP \\
\hline \multicolumn{3}{|c|}{12} & & \multicolumn{2}{|l|}{4} & \multicolumn{2}{|c|}{34,66} & 9,81 \\
\hline
\end{tabular}

Quadro 1: Características dos informantes. Fonte: Autora

Conforme representa o Quadro anterior, dos informantes selecionados para o grupo experimental, seis (6) são nativos da Argentina, três (3) do sexo feminino e três (3) do sexo masculino; e seis (6) são nativos do Uruguai, três

3 A coleta dos dados para a pesquisa foi aprovada pelo Comitê de Ética em Pesquisa da Pontifícia Universidade Católica do Rio Grande do Sul, sob número de registro CEP 11/05426. 
(3) do sexo feminino e três (3) do sexo masculino. Esses informantes, no momento da pesquisa, estavam residindo em Porto Alegre por um tempo mínimo de seis meses. Não se estipulou um tempo máximo de residência no país e, por tal razão, o grupo é bastante heterogêneo quanto a esse aspecto.

Quanto ao grupo controle, que serve apenas como um diagnóstico comparativo, esse é composto por doze (12) informantes, quatro (4) do sexo feminino e oito (8) do sexo masculino. Nesse caso, não se obteve um número igual de informantes para cada sexo, o que, para os objetivos deste estudo, não interfere nos resultados. Salienta-se, entretanto, que as diferenças físicas que incluem o sexo serão controladas por meio da normalização dos dados.

\subsection{Instrumentos}

Os informantes que compõem a amostra dos dois grupos, grupo experimental e grupo controle, participaram de três subsequentes experimentos de produção, a saber, (i) produção de palavras e frases; (ii) nomeação de imagens; (iii) descrição livre de imagens. A aplicação dos testes foi realizada individualmente na casa dos informantes, ou em outro local previamente agendado, com o cuidado de ser um espaço com silêncio, sem presença de outras pessoas e sem interferência de barulhos ambientais. Todas as tarefas foram elaboradas em Power Point e apresentadas aos informantes por meio de Notebook. As entrevistas foram gravadas em aparelho ICD - PX 720 - marca Sony, com taxa de amostragem de 22.050 - 16 bits, e, posteriormente, transferidas para o computador.

Nos dois primeiros instrumentos, aplicados em sequência, aos informantes eram apresentadas, em um primeiro momento, palavras isoladas e frases incompletas (ex.: pagode - sogro >> João e seu saíram para dançar __ N N Nesse caso, o informante era orientado a produzir as duas palavras e, após isso, produzir a frase completando com as palavras. $\mathrm{Na}$ sequência, no segundo teste, aos informantes eram apresentadas imagens previamente selecionadas que correspondiam a itens lexicais específicos (ex.: bola, dedo, cobra), e esses eram orientados a nomear oralmente a imagem. Ao todo, os dois experimentos resultaram na produção de aproximadamente cinquenta e dois (52) vocábulos com vogais médias tônicas, por informante. Além desses vocábulos, foram inseridas quinze (15) palavras distratoras com outras vogais, e vogais médias em outras posições da palavra.

A última tarefa, aplicada em um segundo momento, consistiu de uma narrativa mais livre, conduzida a partir de imagens previamente 
selecionadas. Nesse caso, aos informantes eram apresentadas figuras contextualizadas, e os mesmos eram convidados a descrever livremente a imagem. Ao todo, essa tarefa ocupou um tempo de aproximadamente $20 \mathrm{~min}$ por informante.

\subsection{Procedimentos de Análise}

A produção das vogais médias tônicas do português por falantes nativos do espanhol foi analisada com base nos valores de F1, altura, e de F2, anterioridade. Inicialmente, realizou-se a segmentação das vogais manualmente por meio do Software Praat, versão 5.3.03 (BOERSMA; WEENINK, 2012). Após a segmentação, procedeu-se à análise automática dos formantes, com base nos $40 \%$ da porção central da vogal, por meio de scripts do próprio Praat. Os dados obtidos foram normalizados através do programa Norm - Normalization Vowel, o qual constitui uma ferramenta online que permite normalizar e plotar vogais por meio de diferentes métodos. A opção deste estudo foi realizar a normalização pelo método vogal-intrínseco - Bark Difference Metric, o que se justifica pela sua adequação a trabalhos que envolvem a comparação de diferentes inventários fonológicos (WATT; FABRICIUS; KENDALL, 2010). Para a normalização e a conversão dos dados de Hertz para Bark, utilizou-se, além dos dois primeiros formantes que constituem o foco de análise deste estudo, os valores do terceiro formante, F3.

Após a obtenção dos valores dos dois primeiros formantes, procedeu-se, a partir das médias de F1 e de F2, o cálculo de Distância Euclidiana (DE), em Bark, considerando-se separadamente os pares $[\mathrm{e}]-[\varepsilon]$ e os pares [o] - [0]. Esse procedimento foi realizado com a finalidade de verificar a distância entre vogais médias-baixas e vogais médias-altas na produção de não nativos. Na próxima seção, apresentam-se a descrição e a discussão dos resultados obtidos.

\section{Descrição e discussão dos resultados}

De acordo com os procedimentos metodológicos descritos na seção anterior, a análise dos dados foi desenvolvida a partir dos valores médios de F1 e de F2, normalizados em Bark, para as vogais médias [e], [ $\varepsilon$ ], [o] e [॰] do português, localizadas em posição de acento (seco, seca, sopa, bsta), produzidas por nativos do espanhol, aprendizes do Português Brasileiro como L2. Os valores médios dos dois primeiros formantes, obtidos para esse grupo experimental, são apresentados na Tabela 1 a seguir. 


\begin{tabular}{|c|c|c|c|c|}
\hline F1 & $/ \mathbf{e} /$ & $/ \boldsymbol{\varepsilon} /$ & $/ \mathbf{0} /$ & $/ \mathbf{0} /$ \\
\hline Média & 10,25 & 10,01 & 9,83 & 9,75 \\
\hline Mediana & 10,18 & 10,02 & 9,80 & 9,73 \\
\hline DP & 0,39 & 0,35 & 0,41 & 0,41 \\
\hline F2 & & & & \\
\hline Média & 1,81 & 1,89 & 6,60 & 6,67 \\
\hline Mediana & 1,67 & 1,83 & 6,56 & 6,48 \\
\hline DP & 0,45 & 0,46 & 0,60 & 0,64 \\
\hline
\end{tabular}

Tabela 1: Valores em média e mediana (em Bark) - Grupo Experimental. Fonte: Autora

Com base nos valores obtidos em média para F1 (altura) e para F2 (anterioridade), descritos na tabela anterior, buscou-se verificar a localização das vogais médias produzidas por não nativos (grupo experimental) no espaço vocálico, conforme representa a Figura 1 a seguir. Para a localização das vogais [a], [i] e [u], utilizaram-se, como referência, os valores médios apresentados para essas vogais em Moraes, Callou e Leite (1996), variedade de Porto Alegre 4 .

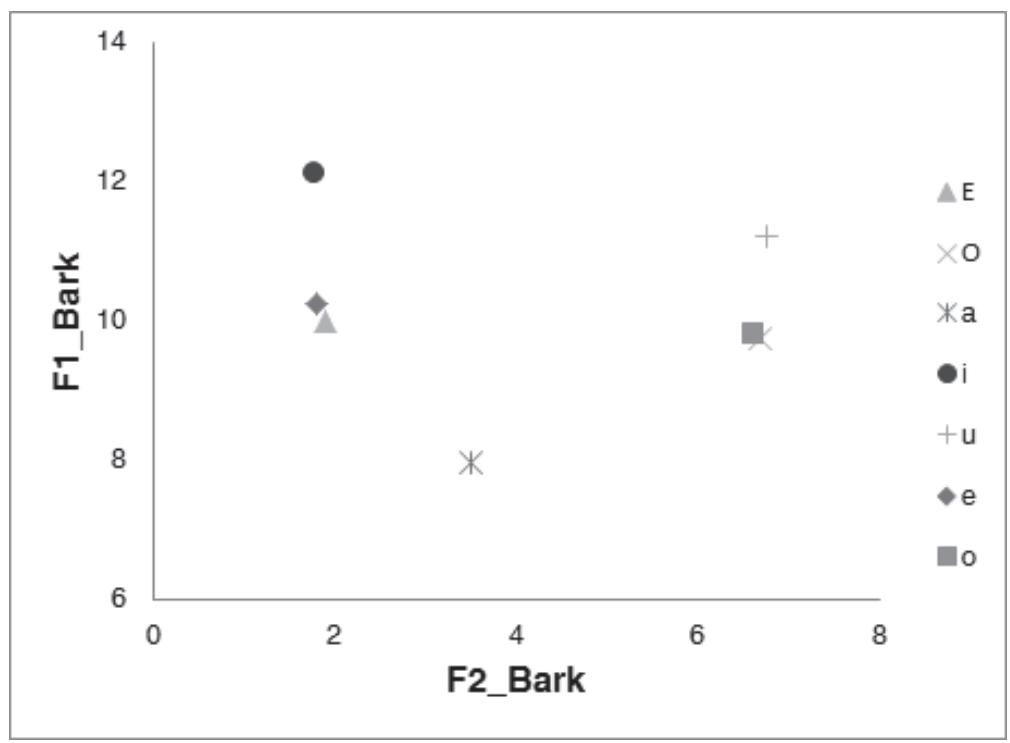

Figura 1: Produção de Vogais Médias - Grupo Experimental. Fonte: Autora

4 Os valores médios de F1 e de F2 apresentados pelos autores foram convertidos de Hertz para Bark neste estudo, a fim de seguir a mesma medida de frequência adotada para as demais vogais. 
A representação anterior permite observar que as vogais médias-baixas [ع] e [॰], produzidas pelo grupo de não nativos, mostram-se muito próximas das vogais médias-altas [e] e [o]. Nota-se, entretanto, que nas vogais anteriores - $[\mathrm{e}] \mathrm{e}[\varepsilon]$ - há uma pequena distância entre as duas vogais, diferentemente do que se observa para as vogais posteriores - [o] e [0], em que as duas categorias se encontram praticamente sobrepostas uma a outra. Embora a distância observada entre as vogais anteriores não chegue a ser contrastiva como no português, aparentemente, os informantes apresentam maior facilidade na produção do contraste entre essas vogais.

Para testar a diferença entre a distância observada entre as vogais [e] e $[\varepsilon]$ em relação à distância entre [o] e [o], procedeu-se o cálculo de Distância Euclidiana, considerando separadamente os dois contrastes. A média obtida, calculada com base nos valores de F1 e de F2, em Bark, indica que há uma distância entre $[\mathrm{e}]$ e $[\varepsilon]$ de 0,33 (DP = 0,41), e de $0,31(\mathrm{DP}=0,15)$ entre [o] e [0]. A diferença entre os dois contrastes, entretanto, não se confirma como significativa, de acordo com o teste Wilcoxon ${ }^{5}(\mathrm{Z}=-1,138, \mathrm{p}=0,255)$.

Os resultados indicam, portanto, que o grupo de não nativos tende a apresentar dificuldade em produzir ambos os tipos de contrastes, vogais médias anteriores $(/ \mathrm{e} / \mathrm{-} / \mathrm{\varepsilon} /)$ e vogais médias posteriores $(/ \mathrm{o} / \mathrm{-} / \mathrm{\jmath} /)$. Na produção desses falantes, o espaço acústico das vogais médias - baixas [ع] e [0], conforme já apontado por estudos anteriores (ALLEGRO, 2010; MACHRY DA SILVA, 2014), tende a coincidir com o espaço acústico das vogais médias-altas - [e] e [o].

Com vistas a verificar o quanto a produção de não nativos difere da produção de falantes nativos, no que tange aos parâmetros de altura e de anterioridade, realizou-se uma comparação das médias obtidas para F1 e F2 de cada uma das vogais médias. As diferenças entre as vogais foram testadas por meio dos testes T para amostras independentes, paramétrico, ou teste Kruskal - Wallis, não paramétrico (nesse caso, quando não atendidos os pressupostos de normalidade e homogeneidade das variâncias). Os resultados obtidos encontram-se descritos na Tabela 2 a seguir.

5 A escolha de testes paramétricos ou não paramétricos foi realizada com base nos testes de normalidade Shapiro-Wilks e Kolmogorov-Smirnov. Sempre que se obteve valor de p >0,05 para os dois ou um dos testes, a escolha foi por aplicar testes paramétricos. Ao contrário, quando os valores obtidos foram de $\mathrm{p}<0,05$, optou-se por testes não paramétricos. 


\begin{tabular}{|c|c|c|c|c|}
\hline Vogal_formante & Média_nativos & Média_não Nativos & Resultado do teste & $\begin{array}{c}\text { Valor de p } \\
\text { (significância) }\end{array}$ \\
\hline F1_e & $\begin{array}{c}10,38 \\
(\mathrm{DP}=0,41)\end{array}$ & $\begin{array}{c}10,25 \\
(\mathrm{DP}=0,39)\end{array}$ & $X^{2}=0,908$ & 0,341 \\
\hline F2_e & $\begin{array}{c}1,84 \\
(\mathrm{DP}=0,23)\end{array}$ & $\begin{array}{c}1,81 \\
(\mathrm{DP}=0,41)\end{array}$ & $X^{2}=1,403$ & 0,236 \\
\hline $\mathrm{F} 1_{-} \varepsilon$ & $\begin{array}{c}8,81 \\
(\mathrm{DP}=0,62)\end{array}$ & $\begin{array}{c}10,01 \\
(\mathrm{DP}=0,35)\end{array}$ & $X^{2}=17,056$ & 0,000 \\
\hline $\mathrm{F} 2 \_\varepsilon$ & $\begin{array}{c}2,21 \\
(\mathrm{DP}=0,44)\end{array}$ & $\begin{array}{c}1,89 \\
(\mathrm{DP}=0,46)\end{array}$ & $X^{2}=3,309$ & 0,049 \\
\hline F1_o & $\begin{array}{c}10,27 \\
(\mathrm{DP}=0,56)\end{array}$ & $\begin{array}{c}9,83 \\
(\mathrm{DP}=0,41)\end{array}$ & $t(22)=-2,065$ & 0,102 \\
\hline F2_o & $\begin{array}{c}7,05 \\
(\mathrm{DP}=0,54)\end{array}$ & $\begin{array}{c}6,60 \\
(\mathrm{DP}=0,60)\end{array}$ & $t(22)=-1,609$ & 0,122 \\
\hline F1_o & $\begin{array}{c}8,52 \\
(\mathrm{DP}=0,47)\end{array}$ & $\begin{array}{c}9,75 \\
(\mathrm{DP}=0,41)\end{array}$ & $\mathrm{t}(22)=6,761$ & 0,000 \\
\hline F2_o & $\begin{array}{c}5,91 \\
(\mathrm{DP}=0,47)\end{array}$ & $\begin{array}{c}6,67 \\
(\mathrm{DP}=0,64)\end{array}$ & $\mathrm{t}(22)=3,291$ & 0,003 \\
\hline
\end{tabular}

Tabela 2: Produção das vogais médias por nativos e não nativos. Fonte: Autora

Os resultados representados na tabela anterior permitem confirmar que não nativos diferem de falantes nativos, em termos de F1 e de F2,

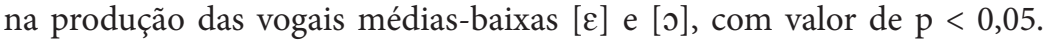
Com relação à produção das vogais médias-altas [e] e [o], não se verifica diferença significativa entre nativos e não nativos; nesse caso, obteve-se $\mathrm{p}>$ 0,05 tanto para F1 quanto para F2 de todas as vogais testadas.

Tais resultados permitem confirmar, conforme hipótese prevista na parte introdutória deste estudo, que falantes nativos do espanhol, variedades da Argentina e do Uruguai, aqui testadas, apresentam dificuldade para produzir o contraste entre os pares de vogais $[\mathrm{e}]-[\varepsilon]$ e $[o]-[0]$, diferindo de nativos do $\mathrm{PB}$ nos parâmetros de altura (F1) e de anterioridade (F2). Na produção de não nativos, as vogais médias-baixas $[\varepsilon]$ e [o] apresentam praticamente a mesma altura e a mesma anterioridade das vogais [e] e [o], o que sugere que, para esses falantes, as categorias fonológicas de vogais médias-baixas, / $/ \varepsilon /$ e $/ \% /$, não se encontram bem definidas em relação às categorias fonológicas das vogais médias-altas, /e/ e /o/, no espaço vocálico. Na Figura 2 a seguir, é possível visualizar a localização das vogais médias produzidas por falantes não nativos (grupo experimental) e falantes nativos (grupo controle). Para as vogais [a], [i] e [u], utilizaram-se como referência, novamente, os valores de Moraes, Callou e Leite (1996), variedade de Porto Alegre. 


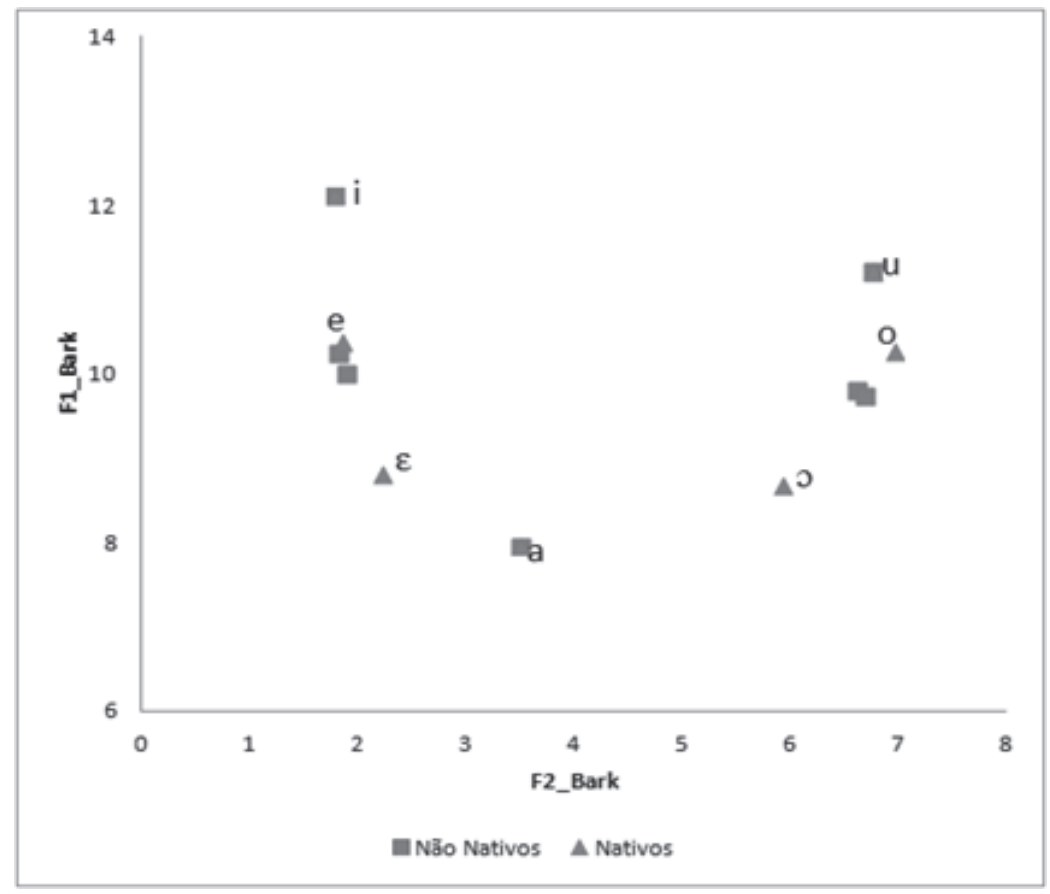

Figura 2: Produção de vogais médias do português (em Bark) - nativos e não nativos. Fonte: Autora

A representação anterior permite observar que, na produção de falantes nativos do $\mathrm{PB}$, há uma distância entre as vogais médias-baixas $[\varepsilon]$ e [o] e as vogais médias-altas [e] e [o], o que não se verifica na produção de não nativos, em que o espaço acústico das vogais médias-baixas $[\varepsilon] \mathrm{e}$ [॰] praticamente coincide com o espaço das vogais médias-altas [e] e [o]. Conforme relatado anteriormente, na produção de não nativos, observouse uma média de Distância Euclidiana de 0,33 (DP =0,41) entre as vogais anteriores $[\mathrm{e}]-[\varepsilon]$ e de $0,31(\mathrm{DP}=0,15)$ entre as vogais posteriores $[\mathrm{o}]-$ [॰]. Quando medida essa distância na produção dos falantes nativos do PB, obteve-se média de $1,76(\mathrm{DP}=0,37)$ para as vogais anteriores $[\mathrm{e}]-[\varepsilon] \mathrm{e}$ de $1,61(\mathrm{DP}=0,27)$ para as vogais posteriores [o] - [o]. Nota-se, portanto, que na produção de não nativos não se realiza, como no português, o contraste entre médias-baixas e médias-altas. A diferença entre nativos e não nativos no que se refere à Distância Euclidiana entre os pares de vogais é comprovada pelo teste de Mann-Whitney, em que se obteve valor de $\mathrm{p}<0,05$ para ambos os pares de vogais, anteriores e posteriores. 
Os resultados expostos até aqui conduzem à confirmação de que os falantes nativos do espanhol da América, considerando os dois grupos analisados, Argentinos e Uruguaios, apresentam dificuldade para produzir

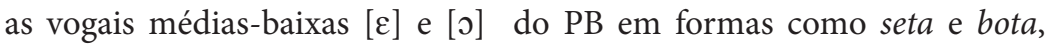
por exemplo. Ou seja, como as categorias de vogais da língua-alvo não se encontram bem definidas, aprendizes produzem as vogais $[\varepsilon]$ e $[0]$ de acordo com os mesmos parâmetros das vogais [e] e [o], também presentes na sua língua nativa.

Não obstante, esses dados revelam o comportamento do grupo como um todo, sem referência ao desempenho de argentinos e uruguaios, separadamente. Nesse sentido, com vistas a investigar possíveis diferenças entre esses dois grupos, quanto à produção das vogais médias do porguguês (L2), procedeu-se à análise dos valores médios de F1 e de F2 apresentados para as vogais $[\mathrm{e}],[\varepsilon],[\mathrm{o}] \mathrm{e}[\mathrm{0}]$, por cada grupo investigado. Os resultados para a média, mediana e desvio padrão obtidos para os nativos da Argentina e os nativos do Uruguai são descritos na Tabela 3 a seguir.

\begin{tabular}{|c|c|c|c|c|c|c|c|c|}
\hline \multicolumn{5}{|c|}{ Nativos da Argentina } & \multicolumn{5}{c|}{ Nativos do Uruguai } \\
\hline F1 & {$[\mathbf{e}]$} & {$[\varepsilon]$} & {$[\mathbf{o}]$} & {$[\mathbf{0}]$} & {$[\mathbf{e}]$} & {$[\varepsilon]$} & {$[\mathbf{0}]$} & {$[\mathbf{0}]$} \\
\hline Média & 10,24 & 10,17 & 9,93 & 9,89 & 10,26 & 9,83 & 9,73 & 9,59 \\
\hline Mediana & 10,19 & 10,18 & 9,89 & 9,91 & 10,13 & 9,74 & 9,70 & 9,54 \\
\hline DP & 0,29 & 0,36 & 0,48 & 0,53 & 0,51 & 0,26 & 0,48 & 0,20 \\
\hline & & & & & & & & \\
\hline F2 & {$[\mathbf{e}]$} & {$[\varepsilon]$} & {$[\mathbf{0}]$} & {$[\mathbf{0}]$} & {$[\mathbf{e}]$} & {$[\varepsilon]$} & {$[\mathbf{0}]$} & {$[\mathbf{0}]$} \\
\hline Média & 1,91 & 1,98 & 6,75 & 6,81 & 1,70 & 1,80 & 6,46 & 6,52 \\
\hline Mediana & 1,84 & 1,93 & 6,72 & 6,68 & 1,67 & 1,83 & 6,50 & 6,36 \\
\hline DP & 0,63 & 0,63 & 0,72 & 0,80 & 0,17 & 0,23 & 0,44 & 0,46 \\
\hline
\end{tabular}

Tabela 3: Valores em média e mediana (em Bark) - Argentinos e Uruguaios. Fonte: Autora

De acordo com os valores descritos na tabela anterior, há diferenças na produção das vogais médias com relação ao grupo, nativo da Argentina ou nativo do Uruguai. Aparentemente, pelos valores médios obtidos, as vogais médias-baixas $[\varepsilon]$ e [0] apresentam-se mais baixas na produção de falantes nativos do Uruguai, os quais apresentam média de 9,83 para $[\varepsilon] \mathrm{e}$ de 9,59 para [0]. Verifica-se também diferença em relação ao parâmetro de anterioridade/posterioridade, com tendência à realização menos anterior das vogais $[\varepsilon]$ e [o] na fala de nativos do Uruguai. A localização acústica das vogais médias, de acordo com o grupo, nativos da Argentina e nativos 
do Uruguai, é representada na Figura 3 a seguir. Seguindo-se a estratégia das análises anteriores, são utilizados, para as vogais [a], [i] e [u], os valores de referência das vogais da variedade de Porto Alegre apresentados em Moraes, Callou e Leite (1996).

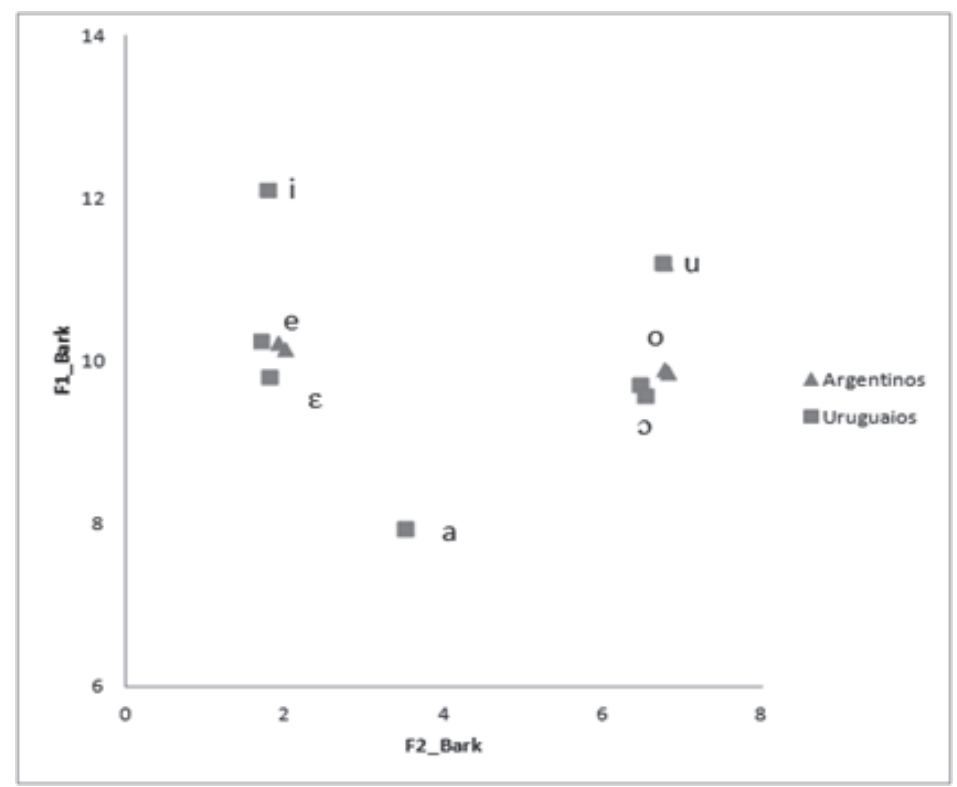

Figura 3: Produção de vogais médias do português (L2) - Argentinos e Uruguaios. Fonte: Autora

A representação gráfica anterior permite observar que na produção de falantes nativos do Uruguai há uma distância um pouco maior, em relação aos nativos da Argentina, entre vogais médias-baixas e vogais médias-altas, principalmente no que se refere às vogais médias anteriores $[e] \mathrm{e}[\varepsilon]$. Por esses resultados, entende-se que o grupo de nativos do Uruguai apresenta-se em estágio mais avançado da aquisição, em comparação aos nativos da Argentina, no que se refere à produção de vogais médias anteriores [e] e $[\varepsilon]$. O mesmo, entretanto, não se pode observar para as vogais posteriores [o] e [o], em que pouca diferença, visivelmente, é notada entre nativos do Uruguai e nativos da Argentina.

Esses resultados conduzem, portanto, a duas inferências, a saber, (i) nativos do Uruguai apresentam maior facilidade na produção do contraste entre vogais médias anteriores do $\mathrm{PB}([\mathrm{e}]-[\varepsilon])$; (ii) nativos do Uruguai Organon, Porto Alegre, v. 30, n. 58, p. 91-108, jan/jun. 2015. 
apresentam melhor desempenho, em relação a falantes nativos da Argentina, no diz respeito à produção das vogais médias do PB, mais precisamente quanto ao contraste entre as vogais médias anteriores $[e]$ e $[\varepsilon]$. Para a confirmação estatística dessas hipóteses, procedeu-se, primeiramente, à comparação dos valores de Distância Euclidiana para nativos do Uruguai, considerando-se, separadamente, os pares de vogais anteriores $([\mathrm{e}]-[\varepsilon])$ e posteriores $([\mathrm{o}]-[\mathrm{o}])$. Posteriormente, procedeu-se à comparação das médias de Distância Euclidiana, para cada par de vogal, em relação ao grupo investigado. $\mathrm{Na}$ Tabela 4, apresentada a seguir, são expostos os valores obtidos em média de Distância Euclidiana para nativos do Uruguai quanto à produção dos dois contrastes, vogais anteriores e vogais posteriores. A diferença entre essas médias, considerando-se somente o grupo de Uruguaios, foi testada a partir do teste paramétrico $t$ para amostras emparelhadas.

\begin{tabular}{|c|c|c|c|}
\hline & $\begin{array}{c}\text { Média de Distância } \\
\text { Euclidiana }\end{array}$ & Resultado do teste & $\begin{array}{c}\text { Valor de } \boldsymbol{p} \\
\text { (significância) }\end{array}$ \\
\hline $\begin{array}{c}\text { Produção do contraste }- \text { vogais } \\
\text { anteriores }[\mathrm{e}]-[\varepsilon]\end{array}$ & $0,50(\mathrm{DP}=0,53)$ & \multirow{2}{*}{$\mathrm{t}(5)=1,508$} & $\mathrm{p}=0,094$ \\
\cline { 1 - 2 } $\begin{array}{c}\text { Produção - vogais posteriores } \\
{[\mathrm{o}]-[\mathrm{o}]}\end{array}$ & $0,39(\mathrm{DP}=0,15)$ & & \\
\hline
\end{tabular}

Tabela 4: Produção do contraste - vogais anteriores e vogais posteriores - Uruguaios. Fonte: Autora

Diante dos resultados descritos na tabela anterior, confirma-se uma diferença marginalmente significativa $(\mathrm{p}=0,094)$ entre a média de Distância Euclidiana observada para vogais médias anteriores $[e]-[\varepsilon]$ e a média de Distância Euclidiana observada para as vogais médias posteriores [o] e [0], na fala de nativos do Uruguai. Tais resultados permitem observar, conforme hipótese anterior, que as categorias de vogais médias-baixas anteriores - $[\mathrm{e}] \mathrm{e}[\varepsilon]$ se encontram melhor definidas para esses informantes em relação às categorias de vogais médias-baixas posteriores - [o] e [0], no que tange aos parâmetros de altura e de anterioridade/posterioridade.

Com relação à segunda hipótese, quanto à diferença dos nativos do Uruguai em relação aos nativos da Argentina, na produção dos contrastes entre vogais médias anteriores e vogais médias posteriores, desenvolveuse, com base nas médias de Distância Euclidiana obtidas, o teste de 
diferenças entre essas médias, considerando-se os grupos separadamente. Os resultados encontram-se descritos na Tabela 5 a seguir.

\begin{tabular}{|c|c|c|c|c|}
\hline & Grupo & Média_DE & Resultado do teste & $\begin{array}{c}\text { Valor de p } \\
\text { (significância) }\end{array}$ \\
\hline \multirow{2}{*}{$\begin{array}{c}\text { Produção do contraste - vogais } \\
\text { anteriores - }[\mathrm{e}]-[\varepsilon]\end{array}$} & Argentina & $\begin{array}{c}0,15 \\
(\mathrm{DP}=0,73)\end{array}$ & $\mathrm{t}(10)=1,594)$ & 0,006 \\
\cline { 2 - 5 } & Uruguai & $\begin{array}{c}0,50 \\
(\mathrm{DP}=0,53)\end{array}$ & 0,040 \\
\hline $\begin{array}{c}\text { Produção do contraste - vogais } \\
\text { posteriores - }[0]-[0]\end{array}$ & Argentina & $\begin{array}{c}0,22 \\
(\mathrm{DP}=0,93)\end{array}$ & \multirow{2}{*}{$\mathrm{t}(10)=-2,530)$} & \\
\cline { 2 - 3 } & Uruguai & $\begin{array}{c}0,39 \\
(\mathrm{DP}=0,15)\end{array}$ & \\
\hline
\end{tabular}

Tabela 5: Comparação entre os grupos - Argentinos e Uruguaios - na produção do contraste. Fonte: Autora

De acordo com os resultados da tabela anterior, é possível observar que nativos do Uruguai apresentam melhor desempenho em relação aos nativos da Argentina na produção de ambos os tipos de contrastes, vogais anteriores $[\mathrm{e}]-[\varepsilon]$ e vogais posteriores $[\mathrm{o}]-[0]$. A média de Distância Euclidiana para as vogais $[\mathrm{e}]$ e $[\varepsilon]$ foi de $0,15(\mathrm{DP}=0,73)$ para nativos da Argentina, e de $0,50(\mathrm{DP}=0,53)$ para nativos do Uruguai. No que se refere às vogais [o] e [0], a média de Distância Euclidiana foi de 0,22 $(\mathrm{DP}=0,93)$ para nativos da Argentina, e de 0,39 $(\mathrm{DP}=0,15)$ para nativos do Uruguai. Em ambos os casos, o teste t para amostras independentes comprova uma diferença significativa entre as médias.

Diante dos resultados expostos, confirma-se que nativos do Uruguai tendem a apresentar uma produção mais acurada do contraste que se observa no português (L2) entre vogais médias-baixas $[e]-[\varepsilon]$ e vogais médias-altas [e] e [o]. Os resultados, entretanto, não permitem confirmar que a realização das vogais pelo grupo de nativos uruguaios seja contrastiva como no português, uma vez que, quando comparadas as médias de Distância Euclidiana obtidas para não nativos, pertencentes ao Uruguai, e nativos do $\mathrm{PB}$, para os pares de vogais [e] - [ع] e [o] - [o], o teste de Mann Whitney aponta para uma diferença significativa com valor de $U=43,00$, $\mathrm{p}=0,010$ para vogais anteriores, e valor de $U=62,00, \mathrm{p}=0,024$ para as vogais posteriores. Ou seja, embora o grupo de nativos do Uruguai tenha apresentado melhor desempenho na produção dos contrastes, em relação ao grupo de nativos da Argentina, o contraste produzido entre as vogais médias ainda não se equipara à produção do falante nativo do Português Brasileiro. 


\section{Considerações Finais}

Diante dos resultados apresentados neste estudo, é possível inferir, conforme hipótese prevista com base em pesquisas anteriores (ALLEGRO, 2010; MACHRY DA SILVA, 2014), que nativos do espanhol da América apresentam dificuldade quanto à produção das vogais médias-baixas do português (L2). Os grupos não nativos analisados, nativos da Argentina e nativos do Uruguai, tendem a realizar as vogais médias-baixas $[\varepsilon]$ e [0] do PB com as características acústicas das vogais médias-altas [e] e [o], também presentes no espanhol. As diferenças entre nativos e não nativos comprovam-se para ambos os parâmetros observados, altura (F1) e anterioridade/posterioridade (F2).

Entretanto, vale ressaltar que quando analisados separadamente os dois grupos de não nativos, uruguaios e argentinos, verifica-se que os nativos do Uruguai, embora não realizem o contraste entre as duas categorias de vogais, médias-altas e médias-baixas, tal como nativos do $\mathrm{PB}$, apresentam uma produção mais acurada das vogais médias-baixas [E] e [0], em relação aos nativos da Argentina. Tal resultado conduz ao entendimento de que, para os nativos do Uruguai, as categorias fonológicas das vogais médias-baixas $(/ \varepsilon /$ e $/ \supset /)$ encontram-se mais bem definidas, com uma realização fonética mais próxima à observada na produção de nativos da língua.

Faz-se importante a ressalva de que as diferenças encontradas entre os dois grupos de não nativos, argentinos e uruguaios, podem estar relacionadas a aspectos individuais de comportamento, não explorados por este estudo. Nesse caso, o que representa ser uma diferença referente ao país de origem, ou à variedade do espanhol, pode ser uma questão das características do grupo quanto a variáveis como frequência de uso do português e exposição diária a essa língua nas situações cotidianas, as quais tendem a exercer forte influência na aprendizagem fonológica de L2 (BEST; TYLER, 2007). Ou seja, o fato de que os nativos do Uruguai tenham apresentado uma produção mais acurada do contraste conduz à premissa de que esses falantes estão mais expostos aos padrões fonológicos do português em relação aos falantes nativos da Argentina. Outras pesquisas são, portanto, necessárias para a investigação dessas hipóteses.

Os dados apresentados no presente estudo oferecem uma contribuição para os estudos relacionados com a aquisição fonético-fonológica do português (L2) por falantes nativos do espanhol, mais precisamente quanto à indicação dos parâmetros acústicos que devem ser adquiridos por esses aprendizes. 


\section{BIBLIOGRAFIA}

ALLEGRO, Fernanda. A relação entre a percepção e produção de sons em espanhol como língua estrangeira (ELE): um estudo de caso. Dissertação (Mestrado em Linguística Aplicada e Estudos da Linguagem). Pontifícia Universidade Católica de São Paulo, 2004.

. A percepção das vogais do português por hispanofalantes: um estudo envolvendo paulistanos e rioplatenses. Revista Intercâmbio. São Paulo, v. 22, p. 56-71, 2010.

ARONSON, Leonor et al. Características acústicas de las vocales del español rioplatense. Fonoaudiológica, Buenos Aires, v. 46, n. 2, p. 12 -20, jul. 2000.

BEST, Catherine; TYLER, Michael. Nonnative and second-language speech perception: commonalities and complementarities. In.: MUNRO, Murray; BOHN, Ocke-Schwen. Language experience in second language speech learning: in honor of James Emil Flege. Amesterdam/ Philadelphia: John Benjamin's Publishing Company, 2007. p. 13 - 34.

FEIDEN, Juliana Andrade; ALVES, Ubiratã Kickhöfel; FINGER, Ingrid. O efeito da anterioridade e da altura na identificação das vogais médias altas e médias baixas do Português Brasileiro por falantes de espanhol. Letras de Hoje, Porto Alegre, v. 49, n. 1, p. 85 - 94, jan. 2014.

FLEGE, James Emil. Second language speech learning theory, findings, and problems. In.: STRANGE, Winifred (ed.). Speech perception and linguistic experience: issues in cross language research. Timonium, MD: York Press, 1995. p. 233 - 277.

. Language contact in bilingualism: Phonetic system interactions. In: COLE, Jennifer; HUALDE, José Ignácio (Eds.). Laboratory Phonology 9. Berlin: Mouton de Gruyter, 2007. p. 353 -380.

MACHRY DA SILVA, Susiele. Aprendizagem fonológica e alofônica em L2: Percepção e produção das vogais médias do português por falantes nativos do espanhol. Tese (Doutorado em Letras). Pontifícia Universidade Católica do Rio Grande do Sul, 2014.

MEIRELLES, Virgínia. Elementos de fonética do português falado no Rio Grande do Sul. Tese (Doutorado em Linguística). Brasilia: Universidade de Brasilia, 2011.

MORAES, João; CALLOU, Dinah; LEITE, Yonne. O sistema vocálico do português do Brasil: caracterização acústica. In.: KATO, Mary (org.). Gramática do português falado. São Paulo: FAPESP, v.5, 2002. p. 33 - 50. NAVARRO, Tomas. Manual de pronunciación española. Madrid: Consejo Superior de Investigaciones Científicas, 1982. 
SANTOS, Giane Rodrigues dos; RAUBER, Andréia. Descrição acústica das vogais do espanhol do Uruguai. Revista X, Curitiba, v. 1, p. 23-34, 2014. STRANGE, Winifred; SHAFER, Valerie. Speech perception in second language learners. In.: EDWARDS, Hansen Jett; ZAMPINI, Mary. Phonology and Second Language Acquisition. Amsterdam: John Benjamins Publishing Company, 2008. p. 153 - 192.

WATT, Dominic; FABRICIUS, Anne; KENDALL, Tyler. More on vowels: plotting and normalization. In.: DI PAOLO, Mariana; YAEGER-DROR, Malcah. Sociophonetics: A student's guide. Routledge: London, 2010. p. 107 -118 .

Recebido em: 30/11/2014. Aceito em: 16/03/2015. 